\title{
Detection and Characterization of Genome-specific Microsatellite Markers in the Allotetraploid
} \section{Prunus serotina}

\author{
Marie Pairon $^{1}$ and Anne-Laure Jacquemart \\ Unité de Génétique, Biodiversity Research Center, Université Catholique de Louvain, Croix du Sud 2, \\ Box 14, B-1348 Louvain-la-Neuve, Belgium \\ Daniel Potter \\ Department of Plant Sciences, Mail Stop 2, University of California, 1 Shields Avenue, Davis, CA \\ 95616
}

\begin{abstract}
AdDITIONAL INDEX WORDS. polyploids, SSR, cross-amplification, Rosaceae, black cherry
Abstract. The utility of microsatellite markers to characterize the genetic diversity of a polyploid species with disomic inheritance is often hampered by the impossibility of determining allele frequencies and the complexity of inheritance patterns. The objective of this study was to solve these problems in the allotetraploid Prunus serotina Ehrh. by finding genome-specific primers (i.e., primers that are specific to one of the two genomes that initially formed the species). Sixty-seven microsatellite primers described in cultivated Prunus L. species were tested for cross-amplification in $P$. serotina, and evidence that conserved markers were genome-specific was found by demonstrating their typical Mendelian diploid inheritance in embryos resulting from controlled crosses. Among the 67 microsatellite markers tested, 26 produced successful amplification and five were genome-specific. No linkage disequilibrium was detected for these loci, but evidence was found for the presence of a null allele at one locus. We found both a high number of alleles per locus (three to 12 ) and a high mean expected heterozygosity (0.71), which were nonsignificantly different from the number of alleles and estimates of expected heterozygosity calculated for three non-genome-specific markers in the same population. The potential use of these genome-specific markers in population genetic studies is discussed.
\end{abstract}

Prunus serotina is a wild, fast-growing tree native to North America (Marquis, 1990) which has been widely planted in European forests and has spread from plantations to invade several types of woodlands and open habitats on poor soils (Muys et al., 1992). Prunus serotina has been classified in subgenus Padus (Miller) Focke (Rehder, 1940), and molecular phylogenetic studies of Prunus place the species in a clade composed of members of that subgenus as well as subgenus Laurocerasus (Duh.) Rehder (Bortiri et al., 2006). Because $P$. serotina is economically important in North America for its timber quality (Marquis, 1990) and ecologically important in Europe owing to its invasive status, questions regarding finescale spatial genetic structure, mating system, or gene flow among populations in both its native and introduced ranges are of interest to foresters and ecologists. Over previous decades, microsatellites have emerged as markers of choice in such analyses because of their high level of polymorphism and their codominant inheritance (Powell et al., 1996). Analyses of polymorphic markers such as microsatellites, however, are

Received for publication 19 Dec. 2007. Accepted for publication 12 Feb. 2008 We thank Marie Jasienuik for facilities provided at UC Davis and Riaz Ahmad for technical assistance.

The journey and stay of Marie Pairon at UC Davis were supported by a grant of the Belgian National Fund of Scientific Research (FNRS). This research was financially supported by the Fonds Spéciaux de Recherche (FSR) of the Université Catholique de Louvain (UCL) (to A-L.J.) and by NSF Grant DEB0515431 (to D.P.)

Marie Pairon is research fellow of the FNRS, and Anne-Laure Jacquemart is research associate in the same institution.

${ }^{1}$ Corresponding author. E-mail address: marie.pairon@uclouvain.be. hindered in allopolyploid species because of the presence of more than two alleles at each locus and the resulting complexity of the inheritance pattern (as reviewed in De Silva et al., 2005; Ronfort et al., 1998).

Allopolyploids have differentiated pairs of chromosomes (homeologous chromosomes) which form bivalents at meiosis, as in their diploid progenitors. Owing to the frequently high relatedness between the ancestral progenitors, multiple alleles are often present in more than one copy. The number of copies at microsatellite loci is, however, impossible to determine because allele dosage cannot be deduced with certainty from band intensities or electropherogram peak marker heights based on a nonquantitative exponential amplification process such as polymerase chain reaction (Markwith et al., 2006). For instance, a tetraploid individual displaying phenotype "ABC" can have any of the following genotypes: "aabc", "abbc", or "abcc". Even if allele dosage were known, it would still be impossible to know at which of two or more duplicated loci a particular allele is actually segregating without performing controlled crosses (Obbard et al., 2006).

To analyze allopolyploid data, allelic phenotypes have therefore been used instead of allelic frequencies to calculate summary statistics (e.g., Becher et al., 2000; Brochmann et al., 1992; Chung et al., 1991). With this approach, phenotypes are treated only as being either different or identical, and it does not make use of all the information held by microsatellite markers. Recently, new estimates of genetic diversity were described to take into account not only the similarity/dissimilarity between individuals but also the number of alleles shared between two individuals (Bruvo et al., 2004; Meirmans and Van Tienderen, 
2004; Obbard et al., 2006). These estimates, however, are not directly comparable to the $F$ statistics (Wright, 1951) more commonly used in diploid organisms, and these techniques do not solve the problem that most population genetic software is written for diploid species.

Not all species that have undergone an allopolyploidization event during their evolution display multiple alleles in more than one copy at duplicated loci. In some cases, duplicated loci may have diverged substantially and may display different expected allele ranges. The analysis can in these cases be done by separating alleles in their diploidized loci, and population statistics can be calculated using the diploidized data (Markwith et al., 2006). In other cases, primers only amplify a single locus of one of the two or more genomes that created the allopolyploid species (hereafter called genome-specific). This is, for instance, the case for the vast majority of microsatellite primers in allopolyploid cultivated species [e.g., Triticum L. spp. (Korzun et al., 1999), Brassica L. spp. (Saal et al., 2001), or Pyrus communis L. (Fernandez-Fernandez et al., 2006)], and the data can be analyzed as if the species were diploids.

So far, five microsatellite markers have been described in black cherry (Downey and Iezzoni, 2000; Pairon and Jacquemart, 2005), among which two amplified both duplicated loci with overlapping expected allele ranges (M4c, Ps12a02), one amplified both loci with different allele ranges (pchpgms 3 ), and two (pchgms2, PceGA34) were genome-specific (Pairon and Jacquemart, 2005).

The main goal of this study was to find additional genomespecific markers in black cherry by selecting conserved microsatellite markers and studying their inheritance patterns in progenies from controlled crosses. The potential usefulness of these genome-specific markers is then tested by characterizing their diversity in 20 individuals from a different population and comparing their information content to that of three previously described non-genome-specific markers in the same population.

\section{Materials and Methods}

\section{Detection of genome-specific markers}

Plant material and DNA extraction. Five controlled crosses were performed on $P$. serotina using five pollen receivers and two pollen donors in June 2004 in an invasive population in Belgium (lat. 50 $41^{\prime} 18^{\prime \prime} \mathrm{N}$, long. 4 $4^{\circ} 43^{\prime} 33^{\prime \prime} \mathrm{E}$ ). Five to 10 twigs of pollen receiver trees, each bearing five up to 13 racemes, were enclosed in nylon mesh bags before anthesis, and crosses were performed by brushing stamens of the pollen donor flowers across the stigma of receptive flowers (details in Pairon and Jacquemart, 2005). Bags were removed when all stigmas of the enclosed racemes were no longer receptive, and fruit were collected unripe in early Aug. 2004 to prevent them from falling and being eaten by birds. DNA was extracted from buds of the seven trees used as pollen donors and receivers using a CTAB extraction protocol (Doyle and Doyle, 1990), and DNA from 30-36 embryos of seeds resulting from the five crosses was extracted using the extraction procedure of Cheung et al. (1993). DNA was extracted from embryos instead of leaves because going through germination would have led to considerable time and seedling loss as fruit had been collected unripe.

PCR AMPlification AND microsatellite anAlysis Sixtyseven microsatellite primer pairs originally designed in Prunus persica (L.) Batsch, Prunus avium L., and Prunus cerasus L.
(Ahmad et al., 2004; Cipriani et al., 1999; Dirlewanger et al., 2002; Sosinski et al., 2000; Struss et al., 2003; Testolin et al., 2000) were tested for cross-species amplification in P. serotina on the seven individuals used as parents in controlled crosses. PCR reactions were performed in $15 \mu \mathrm{L}$ containing $15 \mathrm{ng}$ of template DNA, $2.5 \mathrm{mM} \mathrm{MgCl}_{2}, 0.2 \mathrm{mg} \cdot \mathrm{mL}^{-1} \mathrm{BSA}, 0.1 \mathrm{~mm}$ of each dNTP, $0.5 \mu \mathrm{M}$ of each primer, $0.6 \mathrm{U}$ of Taq DNA polymerase (Roche Diagnostics, Basel, Switzerland), and 1.5 $\mu \mathrm{L}$ of the Taq buffer using a temperature of $94^{\circ} \mathrm{C}$ for $4 \mathrm{~min}$, then 35 cycles of $\left(94{ }^{\circ} \mathrm{C}\right.$ for $25 \mathrm{~s}, 56^{\circ} \mathrm{C}$ for $45 \mathrm{~s}$, and $72{ }^{\circ} \mathrm{C}$ for $45 \mathrm{~s}$ ), and finally $72^{\circ} \mathrm{C}$ for $7 \mathrm{~min}$. Amplification products were electrophoretically separated on $2 \%$ agarose gels.

Forward primers of the 26 primer pairs that successfully produced amplified fragments in $P$. serotina were then fluorescently labeled with either 6-FAM or HEX (Sigma-Aldrich, St. Louis, MO). The same PCR conditions were used and the same seven individuals amplified, and PCR products were analyzed on an ABI-3100 Genetic Analyzer and sized using GeneMapper 3.5 (Applied Biosystems, Foster City, CA).

Because the aim was to find genome-specific markers, inheritance patterns were tested only for loci displaying a maximum number of two alleles in any of the seven parents by genotyping progenies of one controlled cross. The controlled cross to use for each locus was chosen in such a way that the genotypes of the two parents shared no more than one allele at the given locus (Table 1). In these cases, it is possible to determine the frequencies of alleles inherited from each of the two parents in the progenies. Thirty to 36 progenies were screened per marker to evaluate the frequencies of alleles inherited from each of the two parents separately. These observed values were then compared with allelic ratios expected under the diploid hypothesis using $\chi^{2}$ goodness-of-fit tests (SAS version 8.2; SAS Institute, Cary, NC).

\section{Genome-specific markers genetic diversity and information content}

Plant material and microsatellite analysis. To characterize the overall genetic diversity of genome-specific markers and to compare the information content of the genome-specific markers found in this study to that of non-genome-specific markers previously described (pchpgms3, M4c, M12a) (Pairon and Jacquemart, 2005), leaves of 20 unrelated $P$. serotina individuals were collected in a second invasive population (lat. $50^{\circ} 79^{\prime} 03^{\prime \prime} \mathrm{N}$, long. $4^{\circ} 70^{\prime} 73^{\prime \prime} \mathrm{E}$ ), and DNA was extracted using the same CTAB protocol as that used for buds (Doyle and Doyle, 1990).

PCR conditions for amplification of the genome-specific makers were as described above, and the three non-genomespecific markers were as described in Pairon and Jacquemart (2005).

Data Analysis. The genetic variability of the genomespecific markers was estimated by computing the number of alleles $\left(N_{\mathrm{a}}\right)$, the observed heterozygosity $\left(H_{\mathrm{o}}\right)$, and the expected heterozygosity $\left(H_{\mathrm{e}}\right)$ using GeneAlEx (Peakall and Smouse, $2006)$. The fixation index $\left(F_{\text {IS }}\right)$ of Weir and Cockeram was computed using GenePop 3.4 (Raymond and Rousset, 1995). Exact tests for departure from Hardy-Weinberg proportions and tests for linkage disequilibrium were performed using GenePop 3.4.

Because we wanted to test how informative the newly found genome-specific markers were compared with previously defined non-genome specific markers, we computed $N_{\mathrm{a}}, H_{\mathrm{o}}$, 
Table 1. Phenotypes of seven Prunus serotina individuals used as pollen receivers (italic numbers 1-5) and pollen donors (underscored numbers 6 and 7) in the five controlled crosses performed $(1 \times 7,2 \times 6,3 \times 7,4 \times 6,5 \times 6)$ to study the inheritance pattern of five putatively genome-specific microsatellite markers. ${ }^{\mathrm{Z}}$

\begin{tabular}{|c|c|c|c|c|c|c|c|c|c|}
\hline \multirow[b]{2}{*}{ Locus } & \multicolumn{2}{|c|}{ Allele } & \multicolumn{7}{|c|}{ Individuals } \\
\hline & $\overline{\text { Size (bp) }}$ & $\operatorname{Code}^{y}$ & 1 & 2 & 3 & 4 & 5 & 6 & 7 \\
\hline \multirow[t]{7}{*}{$\mathrm{UCD}^{-\mathrm{CH}} 14^{\mathrm{x}}$} & 136 & & & & $x$ & & & & \\
\hline & 138 & A & $\times$ & & & & & & \\
\hline & 142 & & & & & & $x$ & $x$ & \\
\hline & 148 & B & $x$ & $x$ & $\times$ & $x$ & & $x$ & \\
\hline & 156 & $\mathrm{C}$ & & $x$ & & & & & $x$ \\
\hline & 158 & & & & & & $\times$ & & \\
\hline & 160 & & & & & $x$ & & & \\
\hline \multirow[t]{4}{*}{$\mathrm{UCD}-\mathrm{CH} 24^{\mathrm{x}}$} & 78 & & & $x$ & & & & & \\
\hline & 80 & $\mathrm{D}$ & $\times$ & $x$ & $x$ & $x$ & $x$ & $x$ & \\
\hline & 82 & $\mathrm{~F}$ & & & & $x$ & $x$ & & $\times$ \\
\hline & 84 & $\mathrm{E}$ & & & $x$ & & & & \\
\hline \multirow[t]{4}{*}{ UDP96-005 } & 82 & I & & & $x$ & & $x$ & $x$ & \\
\hline & 84 & G & $\times$ & $x$ & & & & & \\
\hline & 86 & & & & & $x$ & & & $\times$ \\
\hline & 88 & $\mathrm{H}$ & $x$ & $\times$ & & & & & \\
\hline \multirow[t]{5}{*}{ UDP98-025 } & 109 & $\mathrm{~L}$ & $\times$ & & & & $x$ & $x$ & \\
\hline & 117 & $\mathrm{~J}$ & $\times$ & $x$ & & & & & \\
\hline & 119 & M & & & & $x$ & & $x$ & \\
\hline & 121 & & & & $\times$ & & $x$ & & $x$ \\
\hline & 127 & K & & $x$ & & & & & \\
\hline \multirow[t]{3}{*}{ UDP98-405 } & 111 & $\mathrm{P}$ & & & & & & & $x$ \\
\hline & 113 & $\mathrm{~N}$ & $x$ & $x$ & $\times$ & $x$ & & $x$ & $x$ \\
\hline & 115 & $\mathrm{O}$ & $x$ & & & $x$ & $x$ & $x$ & \\
\hline
\end{tabular}

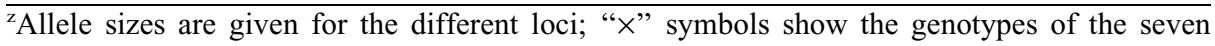
individuals. Shaded cells highlight the two individuals chosen as parents in the controlled crosses used to test the marker inheritance at each locus.

${ }^{\mathrm{y}}$ Letter code used to characterize the expected and observed allelic ratios in Table 3.

${ }^{\mathrm{x}}$ Struss et al. (2003).

"Testolin et al. (2000).

${ }^{v}$ Cipriani et al. (1999).

and an estimate of $H_{\mathrm{e}}\left(H_{P H E N}\right)$ for the non-genome-specific markers. The observed heterozygosity $\left(H_{\mathrm{o}}\right)$ was computed assuming that an individual was heterozygote when it displayed a minimum of two different alleles at a locus. $H_{\text {PHEN }}$ was computed using allelic phenotypes instead of allelic frequencies as follows:

$$
H_{\mathrm{PHEN}}=\left(1-\sum g_{i}^{2}\right)
$$

where $g_{i}$ is the frequency of the $i$ th phenotype. Note that this is equal to the equation of the discrimination power (e.g., Kloosterman et al., 1993). For comparison purposes, $H_{P H E N}$ was also evaluated for the genome-specific markers using Eq. [1].

Student's $t$ tests were performed to compare values of $N_{\mathrm{a}}$, $H_{\mathrm{o}}$, and $H_{P H E N}$ for the genome-specific and non-genomespecific markers (SAS version 8.2).

\section{Results}

DETECTION OF GENOME-SPECIFIC MARKERS. PCR amplification was considered to be successful when an amplicon of sharp intensity and in the expected size range was visible on agarose gels. Using such a criterion, 26 out of $67(39 \%)$ microsatellite loci gave apparently correct PCR amplification in P. serotina.

Of the 26 primer pairs that yielded specific bands of sharp intensity on agarose gels, five were monomorphic, three displayed unreliable PCR amplifications, 13 gave a maximum number of four alleles per individual (Table 2), and five $(19 \%)$ displayed a maximum number of two alleles per individual (Table 3). The patterns observed were not correlated to the species in which the primer pairs were initially developed. Markers designed for $P$. avium and $P$. persica displayed all four patterns described above.

Inheritance patterns were tested for the five loci displaying a maximum of two alleles per individual. The alleles inherited from each of the two parents by $30-36$ progenies per locus were compared with the allelic ratios expected in a diploid species (Table 3). There was no difference between expected and observed ratios as $P$ values of $\chi^{2}$ tests were all nonsignificant (Table 3). Locus UCD-CH24 was different from the four other loci because of a particular pattern observed in the allele segregation of one of the two parents. The pollen donor displayed a homozygote phenotype with a unique allele $(\mathrm{F})$ at this locus. However, this unique allele was only found in $56 \%$ of the progenies, instead of being found in $100 \%$ of the progenies as would be expected from a homozygote genotype (ff). The only way to explain these proportions is to account for a null allele in the pollen donor genotype $(f-)$ (Table 3$)$.

GENOME-SPECIFIC MARKERS' GENETIC DIVERSITY AND INFORMATION CONTENT. The genetic variability of these genome-specific markers was tested by screening 20 individuals in a second population. They all showed high information content, with a total number of alleles ranging from three to 12 and average observed and expected heterozygosities of 0.56 and 0.71 , respectively (Table 4). The presence of a null allele at locus UCD-CH24 was further demonstrated by its significant departure from HardyWeinberg genotypic proportions $(P<0.01)$ in this population (Table 4). This test was not significant for the four other genome-specific loci (Table 4), and none of the locus pairs showed significant linkage disequilibrium $(P>0.1)$.

The genetic diversity of these genome-specific markers was then compared with that of the non-genome-specific markers on the same 20 individuals. The average number of alleles per locus and $H_{P H E N}$ were not significantly different from those of the non-genome-specific markers $(P=0.12$, Table 4). The observed heterozygosity was significantly higher for the non-genome-specific markers because having a homozygous genotype is much more likely at genomespecific loci. In order for $H_{\mathrm{o}}$ to be different from one in the case of non-genome-specific markers, both duplicated loci need indeed to be homozygous and have the same allele, which was never found in all three non-genome-specific loci in our study. 
Table 2. Results of cross-amplification tests and level of polymorphism in Prunus serotina for 21 Prunus persica, Prunus avium, and Prunus cerasus microsatellite primers that were not genomespecific but showed good polymorphism (polymorphic), were monomorphic (monomorphic), or showed unreliable PCR amplification (poor amplification).

\begin{tabular}{|c|c|c|c|}
\hline Locus & Origin & $\begin{array}{l}\text { Amplification } \\
\text { in } P \text {. serotina }\end{array}$ & $\begin{array}{c}\text { Size range }(\mathrm{bp}) \\
\text { in } P \text {. serotina }\end{array}$ \\
\hline$\overline{\text { BBPCT-002z }}$ & P. persica & Polymorphic & 179-191 \\
\hline ВВРСТ-017z & P. persica & Polymorphic & $316-364$ \\
\hline ВВРСТ-024 & P. persica & Polymorphic & $92-96$ \\
\hline ВBPCТ $-025^{z}$ & P. persica & Polymorphic & $188-206$ \\
\hline ВРРСТ-007z & P. persica & Monomorphic & 149 \\
\hline ВРРСТ-033 & P. persica & Monomorphic & 144 \\
\hline UCD-CH11 ${ }^{\mathrm{y}}$ & P. avium & Polymorphic & $78-118$ \\
\hline UCD-CH13 & P. avium & Monomorphic & 120 \\
\hline UCD-CH15 & P. avium & Poor amplification & 一 \\
\hline UCD-CH19y & P. avium & Poor amplification & - \\
\hline PS01H03 ${ }^{x}$ & P. cerasus & Poor amplification & - \\
\hline PS08E08 ${ }^{x}$ & P. cerasus & Monomorphic & 135 \\
\hline $\mathrm{PS} 7 \mathrm{~A} 02^{\mathrm{x}}$ & P. cerasus & Polymorphic & $66-92$ \\
\hline UDP96-001 ${ }^{\mathrm{w}}$ & P. persica & Polymorphic & $97-107$ \\
\hline UDP96-019w & P. persica & Polymorphic & $202-236$ \\
\hline UDP97-402w & P. persica & Polymorphic & $123-145$ \\
\hline UDP98-022v & P. persica & Polymorphic & $112-138$ \\
\hline UDP98-406 & P. persica & Polymorphic & $77-101$ \\
\hline UDP98-408w & P. persica & Polymorphic & $65-406$ \\
\hline UDP98-410 & P. persica & Monomorphic & 114 \\
\hline UDP98-416 & P. persica & Polymorphic & $102-106$ \\
\hline
\end{tabular}

${ }^{\mathrm{z}}$ Dirlewanger et al. (2002).

${ }^{\mathrm{y}}$ Struss et al. (2003).

'Sosinski et al. (2000).

${ }^{\mathrm{w}}$ Testolin et al. (2000).

${ }^{\mathrm{v}}$ Cipriani et al. (1999).

\section{Discussion}

We demonstrated here that $39 \%$ of microsatellite flanking regions described in cultivated Prunus species were conserved in the wild $P$. serotina. Among the conserved primers that showed polymorphism, $50 \%$ amplified both duplicated loci and $19 \%$ were genome-specific.

The primer pairs that were found to amplify only a single locus from one of the two ancestral genomes present in $P$. serotina were derived from $P$. persica (UDP96-005, UDP98-025, UDP98-405) (Cipriani et al., 1999; Testolin et al., 2000) and P. avium (UCD-CH14, UCD-CH24) (Ahmad et al., 2004; Struss et al., 2003). UDP96-005 and UDP98-405 had previously been tested for cross-amplification in several cultivated species (Cipriani et al., 1999) classified in different subgenera of Prunus (e.g., Rehder, 1940). They were shown to be conserved in species of subgenera Amygdalus (L.) Focke [e.g., P. persica, Prunus dulcis (Miller) D.A. Webb], Prunus (e.g., Prunus armeniaca L.), and Cerasus (Miller) Focke (e.g., $P$. avium and $P$. cerasus), indicating a high degree of conservation across the genus, which was further confirmed by their utility in P. serotina (subgenus Padus). Recent phylogenetic studies (e.g., Bortiri et al., 2006) have suggested that species of subgenera Padus and Laurocerasus form a clade separated from the rest of the genus, implying greater divergence between the former species and the crop plants in which the microsatellite markers were developed than among the different crop species and cultivars. This provides a possible explanation as to why some of the primers were not conserved in one of the two duplicated loci in black cherry. A more detailed study of the subgenera is needed, however, to correctly infer the putative parental species.

All genome-specific markers except UCD-CH14 and UCDCH24 have been placed on a map covering the Prunus genome by Aranzana et al. (2003). They do not seem to be restricted to one single region of the genome as locus UDP96-005 is found on G1, UDP98-025 on G2, and UDP98-405 on G7. Therefore, the presence of genome-specific microsatellite loci does not seem to be correlated to the locus position in the genome, which would be expected if part of the genome is becoming diploidized as is sometimes observed with polyploids (Bretagnolle, 1998).

The genetic variability of these new genome-specific markers was high (mean $H_{\mathrm{e}}=0.71$ ) when compared with values reported for cultivated diploid Prunus species [e.g.,

Table 3. Inheritance analysis results at the five microsatellite loci that displayed a maximum of two alleles in the seven Prunus serotina parental individuals. ${ }^{\mathrm{z}}$

\begin{tabular}{|c|c|c|c|c|c|c|c|}
\hline Locus & Parent code & $\begin{array}{c}\text { Parent } \\
\text { phenotype }\end{array}$ & $\begin{array}{l}\text { Putative parent } \\
\text { genotype }^{\mathrm{x}}\end{array}$ & $\begin{array}{c}\text { Expected } \\
\text { gamete ratios }\end{array}$ & $\begin{array}{l}\text { Observed gamete } \\
\text { genotype }\end{array}$ & $\chi^{2}$ & $P$ \\
\hline \multirow[t]{2}{*}{ UCD-CH14 } & 1 & $\mathrm{AB}$ & $a b /-$ & $1 \mathrm{a}: 1 \mathrm{~b}$ & $17 a: 15 b$ & 0.13 & 0.84 \\
\hline & 7 & $\mathrm{C}$ & $\mathrm{cc} /-$ & $1 \mathrm{c}$ & $32 \mathrm{c}$ & $\mathrm{NA}^{\mathrm{w}}$ & - \\
\hline & 7 & $\mathrm{~F}$ & $\mathrm{f}-/-$ & 1f : $1-$ & $18 \mathrm{f}: 14$ & 0.5 & 0.6 \\
\hline \multirow[t]{2}{*}{ UDP96-005 } & 2 & GH & $\mathrm{gh} /-$ & $1 \mathrm{~g}: 1 \mathrm{~h}$ & $18 \mathrm{~g}: 18 \mathrm{~h}$ & 0 & 1 \\
\hline & 6 & I & ii/- & $1 \mathrm{i}$ & $36 \mathrm{i}$ & NA & - \\
\hline & 6 & LM & $\operatorname{lm} /-$ & $11: 1 \mathrm{~m}$ & $201: 14 m$ & 1.06 & 0.39 \\
\hline \multirow[t]{2}{*}{ UDP98-405 } & 1 & NO & no/- & 1n: 10 & 19n : 11o & 2.13 & 0.2 \\
\hline & 7 & NP & $\mathrm{np} /-$ & $1 \mathrm{n}: 1 \mathrm{p}$ & $16 n: 14 p$ & 0.13 & 0.84 \\
\hline
\end{tabular}

${ }^{\mathrm{z}}$ The phenotypes of the two parents used for the controlled crosses are given and the observed gamete genotypes are compared with the gamete ratios expected under the hypothesis of genome-specific marker.

${ }^{y}$ Letter codes as described in Table 1. Note that cap letters represent phenotypes and lowercase letters represent genotypes.

"The "/" represents separation between two duplicated loci that segregate disomically at meiosis and that come from each of the two ancestral genomes that initially formed the allotetraploid.

"NA" is a reminder that $\chi^{2}$ tests are not possible when there is only one possible expected value. 
Table 4. Characterization of the five genome-specific loci described in this study and of the three non-genome-specific loci previously described in an invasive population of Prunus serotina $\left(n=20\right.$ individuals) ${ }^{\mathrm{z}}$

\begin{tabular}{|c|c|c|c|c|c|c|c|c|}
\hline Marker & Locus & Origin & Size range (bp) & $N_{\mathrm{a}}$ & $H_{\mathrm{o}}$ & $H_{\text {PHEN }}$ & $H_{\mathrm{e}}$ & $F_{\text {IS }}$ \\
\hline \multirow[t]{5}{*}{ Genome-specific } & UCD-CH14y & P. avium & $136-164$ & 12 & 0.80 & 0.94 & 0.87 & 0.10 \\
\hline & $\mathrm{UCD}-\mathrm{CH} 24^{y}$ & P. avium & $80-106$ & 8 & 0.32 & 0.88 & 0.84 & $0.64^{\mathrm{x}}$ \\
\hline & UDP96-005 & P. persica & $82-88$ & 4 & 0.55 & 0.77 & 0.60 & 0.10 \\
\hline & UDP98-405 & P. persica & 113-119 & 3 & 0.50 & 0.59 & 0.43 & -0.13 \\
\hline & Average & & & 7.20 & 0.56 & 0.82 & 0.71 & - \\
\hline \multirow[t]{3}{*}{ Non-genome-specific } & $\mathrm{M} 4 \mathrm{c}^{\mathrm{u}}$ & P. persica & $65-85$ & 8 & 1 & 0.94 & - & - \\
\hline & $\operatorname{Ps} 12 \mathrm{a} 02^{\mathrm{t}}$ & P. avium & $145-187$ & 14 & 1 & 0.94 & - & - \\
\hline & Average & & & 12 & 1 & 0.94 & - & - \\
\hline$t$ & & & & -1.81 & -5.44 & -1.99 & - & - \\
\hline$P$ & & & & 0.12 & 0.005 & 0.12 & - & - \\
\hline
\end{tabular}

${ }^{z}$ Size range, number of alleles $\left(N_{\mathrm{a}}\right)$, observed heterozygosity $\left(H_{\mathrm{o}}\right)$, and estimate of expected heterozygosity following Eq. [1] described in Materials and Methods $\left(H_{P H E N}\right)$ are given for both types of markers. True expected heterozygosity $\left(H_{\mathrm{e}}\right)$ and fixation index $\left(F_{\mathrm{IS}}\right)$ were computed only for genome-specific markers.

${ }^{y}$ Struss et al. (2003).

${ }^{x}$ Exact test of departure from Hardy-Weinberg proportions is significant $(P<0.01)$.

${ }^{w}$ Testolin et al. (2000).

${ }^{\mathrm{v}}$ Cipriani et al. (1999).

"Yamamoto et al. (2002).

tDowney and Iezzoni (2000).

mean $H_{\mathrm{e}}=0.47$ in P. persica (Testolin et al., 2000) or mean $H_{\mathrm{e}}=$ 0.60 in $P$. avium (Dirlewanger et al., 2002)], or even for wild $P$. avium accessions [mean $H_{\mathrm{e}}=0.60$ (Vaughan and Russell, 2004)].

Interpreting data from non-genome-specific markers as allelic phenotypes as we did when calculating $H_{P H E N}$, has limited use when it comes to comparing estimates of genetic diversity between diploid and polyploid species. The estimate of expected heterozygosity, $H_{P H E N}$, does not recognize the greater similarity of phenotypes that share more alleles over those that share fewer (e.g., Obbard et al., 2006). New estimates that try to take this particularity into account (e.g., Bruvo et al., 2004; Meirmans and Van Tienderen, 2004; Obbard et al., 2006) have not been compared with estimates of genetic diversity traditionally computed in diploid organisms [e.g., $F$ statistics (Wright, 1951)] in real populations because, to date, no studies has found both genome-specific and non-genome-specific markers in the same species. We have shown here that these two types of markers can be used to generate both genomespecific genotypes that can be analyzed as diploid genotypes and non-genome-specific phenotypes for the same populations of the wild tree species $P$. serotina. It is therefore possible to test the difference between allopolyploid estimates of genetic diversity and differentiation, computed using non-genomespecific markers, and traditional $F_{\mathrm{ST}}$ values or other diploid estimates of genetic diversity, computed using genome-specific markers on the same individuals. This could be helpful to assess the quality of estimates of heterozygosity and $F_{\mathrm{ST}}$-like statistics designed for polyploid organisms.

Aside from the potential interest this could have on the study of estimates of genetic diversity of polyploids in general, the newly found genome-specific primers can be used together with the two genome-specific primers previously described (pchgms2, PceGA34) (Pairon and Jacquemart, 2005) and locus pchpgms 3 that amplified both loci with different allele ranges to study population genetic structure or perform assignment tests on $P$. serotina, with the same power as if the species were diploid. These will be useful, for instance, to predict and model the species establishment in new habitats and describe the overall genetic structure of the species in its native and invasive ranges to detect founder effects or describe historical patterns of introduction in Europe.

\section{Literature Cited}

Ahmad, R., D. Potter, and S.M. Southwick. 2004. Identification and characterization of plum and pluot cultivars by microsatellite markers. J. Hort. Sci. Biotechnol. 79:164-169.

Aranzana, M., A. Pineda, P. Cosson, E. Dirlewanger, J. Ascasibar, G. Cipriani, C. Ryder, R. Testolin, A. Abbott, G. King, A. Iezzoni, and P. Arus. 2003. A set of simple-sequence repeat (SSR) markers covering the Prunus genome. Theor. Appl. Genet. 106:819-825.

Becher, S.A., K. Steinmetz, K. Weising, S. Boury, D. Peltier, J.-P. Renou, G. Kahl, and K. Wolff. 2000. Microsatellites for cultivar identification in Pelargonium. Theor. Appl. Genet. 101:643-651.

Bortiri, E., B. Vanden Heuvel, and D. Potter. 2006. Phylogenetic analysis of morphology in Prunus reveals extensive homoplasy. Plant Syst. Evol. 259:53-71.

Bretagnolle, F. 1998. La polyploïdie chez les plantes. Bot. Helvetica 108:5-37.

Brochmann, C., P.S. Soltis, and D.E. Soltis. 1992. Recurrent formation and polyphyly of nordic polyploids in Draba (Brassicaceae). Amer. J. Bot. 79:673-688.

Bruvo, R., N.K. Michiels, T.G. D'Souza, and H. Schulenburg. 2004. A simple method for the calculation of microsatellite genotype distances irrespective of ploidy level. Mol. Ecol. 13:2101-2106.

Cheung, W.Y., N. Hubert, and B.S. Landry. 1993. A simple and rapid DNA microextraction method for plant, animal, and insect suitable for RAPD and other PCR analyses. PCR Methods Appl. 3:69-70.

Chung, M.G., J.L. Hamrick, S.B. Jones, and G.S. Derda. 1991. Isozyme variation within and among populations of Hosta (Liliaceae) in Korea. Syst. Bot. 16:667-684.

Cipriani, G., G. Lot, W.G. Huang, M.T. Marrazzo, E. Peterlunger, and R. Testolin. 1999. AC/GT and AG/CT microsatellite repeats in peach [Prunus persica (L) Batsch]: Isolation, characterisation and crossspecies amplification in Prunus. Theor. Appl. Genet. 99:65-72. 
De Silva, H.N., A.J. Hall, E. Rikkerink, M.A. McNeilage, and L.G. Fraser. 2005. Estimation of allele frequencies in polyploids under certain patterns of inheritance. Heredity 95:327-334.

Dirlewanger, E., P. Cosson, M. Tavaud, M. Aranzana, C. Poizat, A. Zanetto, P. Arus, and F. Laigret. 2002. Development of microsatellite markers in peach (Prunus persica (L.) Batsch) and their use in genetic diversity analysis in peach and sweet cherry (Prunus avium L.). Theor. Appl. Genet. 105:127-138.

Downey, S.L. and A.F. Iezzoni. 2000. Polymorphic DNA markers in black cherry (Prunus serotina) are identified using sequences from sweet cherry, peach, and sour cherry. J. Amer. Soc. Hort. Sci. 125:76-80.

Doyle, J.J. and J.L. Doyle. 1990. Isolation of plant DNA from fresh tissue. Focus 12:13-15.

Fernandez-Fernandez, F., N.G. Harvey, and C.M. James. 2006. Isolation and characterization of polymorphic microsatellite markers from european pear (Pyrus communis L.). Mol. Ecol. Notes 6:10391041.

Kloosterman, A.D., B. Budowle, and P. Daselaar. 1993. PCR amplification and detection of the human D1S80 Vntr locus-Amplification conditions, population genetics and application in forensic analysis. Intl. J. Legal Med. 105:257-264.

Korzun, V., M.S. Roder, K. Wendehake, A. Pasqualone, C. Lotti, M.W. Ganal, and A. Blanco. 1999. Integration of dinucleotide microsatellites from hexaploid bread wheat into a genetic linkage map of durum wheat. Theor. Appl. Genet. 98:1202-1207.

Markwith, S.H., D.J. Stewart, and J.L. Dyer. 2006. TETRASAT: A program for the population analysis of allotetraploid microsatellite data. Mol. Ecol. Notes 6:586-589.

Marquis, D. 1990. Prunus serotina Ehrh. Black cherry, p. 594-602. In: Silvics of North America, Vol. 2: Hardwoods. U.S. Dept. Agr., For. Serv., Washington, D.C.

Meirmans, P.G. and P.H. Van Tienderen. 2004. GENOTYPE and GENODIVE: Two programs for the analysis of genetic diversity of asexual organisms. Mol. Ecol. Notes 4:792-794.

Muys, B., D. Maddelein, and N. Lust. 1992. Ecology, practice and policy of black cherry (Prunus serotina Ehrh.) management in Belgium. Silva Gandavensis 27:28-45.

Obbard, D.J., S.A. Harris, and J.R. Pannell. 2006. Simple allelicphenotype diversity and differentiation statistics for allopolyploids. Heredity 97:296-303.
Pairon, M.C. and A.L. Jacquemart. 2005. Disomic segregation of microsatellites in the tetraploid Prunus serotina Ehrh. (Rosaceae). J. Amer. Soc. Hort. Sci. 130:729-734.

Peakall, R. and P.E. Smouse. 2006. GENALEX 6: Genetic analysis in Excel. Population genetic software for teaching and research. Mol. Ecol. Notes 6:288-295.

Powell, W., G. Machray, and J. Provan. 1996. Polymorphism revealed by simple sequence repeat. Trends Plant Sci. 1:215-221.

Raymond, M. and F. Rousset. 1995. GENEPOP-Population genetics software for exact tests and ecumenicism. J. Hered. 86:248-249.

Rehder, A. 1940. Rosaceae Prunus, p. 452-481. In: A. Rehder (ed.). Manual of cultivated trees and shrubs hardy in North America. 2nd ed. Macmillan, New York.

Ronfort, J.L., E. Jenczewski, T. Bataillon, and F. Rousset. 1998. Analysis of population structure in autotetraploid species. Genetics 150:921-930.

Saal, B., J. Plieske, J. Hu, C.F. Quiros, and D. Struss. 2001. Microsatellite markers for genome analysis in Brassica. II. Assignment of rapeseed microsatellites to the $\mathrm{A}$ and $\mathrm{C}$ genomes and genetic mapping in Brassica oleracea L. Theor. Appl. Genet. 102:695-699.

Sosinski, B., M. Gannavarapu, L.D. Hager, L.E. Beck, G.J. King, C.D. Ryder, S. Rajapakse, W.V. Baird, R.E. Ballard, and A.G. Abbott. 2000. Characterization of microsatellite markers in peach [Prunus persica (L.) Batsch]. Theor. Appl. Genet. 101:421-428.

Struss, D., R. Ahmad, S.M. Southwick, and M. Boritzki. 2003. Analysis of sweet cherry (Prunus avium L.) cultivars using SSR and AFLP markers. J. Amer. Soc. Hort. Sci. 128:904-909.

Testolin, R., T. Marrazzo, G. Cipriani, R. Quarta, I. Verde, M.T. Dettori, M. Pancaldi, and S. Sansavini. 2000. Microsatellite DNA in peach (Prunus persica L. Batsch) and its use in fingerprinting and testing the genetic origin of cultivars. Genome 43:512-520.

Vaughan, S.P. and K. Russell. 2004. Characterization of novel microsatellites and development of multiplex PCR for large-scale population studies in wild cherry, Prunus avium. Mol. Ecol. Notes 4:429-431.

Wright, S. 1951. The genetical structure of populations. Ann. Eugenet. 15:223-254.

Yamamoto, T., K. Mochida, T. Imai, Y. Shi, I. Ogiwara, and T. Hayashi. 2002. Microsatellite markers in peach (Prunus persica (L.) Batsch) derived from an enriched genomic and cDNA libraries. Mol. Ecol. Notes 2:298-301. 